\title{
Fabrication of optochemical and electrochemical sensors using thin films of porphyrin and phthalocyanine derivatives
}

\author{
PALANISAMY KALIMUTHU, ARUMUGAM SIVANESAN and S ABRAHAM JOHN* \\ Centre for Nanoscience and Nanotechnology, Department of Chemistry, Gandhigram Rural Institute, \\ Gandhigram, Dindigul 634 302, India \\ e-mail: abrajohn@yahoo.co.in
}

\begin{abstract}
This paper describes the fabrication of thin films of porphyrin and metallophthalocyanine derivatives on different substrates for the optochemical detection of $\mathrm{HCl}$ gas and electrochemical determination of L-cysteine $(\mathrm{CySH})$. Solid state gas sensor for $\mathrm{HCl}$ gas was fabricated by coating meso-substituted porphyrin derivatives on glass slide and examined optochemical sensing of $\mathrm{HCl}$ gas. The concentration of gaseous $\mathrm{HCl}$ was monitored from the changes in the absorbance of Soret band. Among the different porphyrin derivatives, meso-tetramesitylporphyrin (MTMP) coated film showed excellent sensitivity towards $\mathrm{HCl}$ and achieved a detection limit of $0.03 \mathrm{ppm} \mathrm{HCl}$. Further, we have studied the self-assembly of 1,8,15,22tetraaminometallophthalocyanine ( $4 \alpha-\mathrm{MTAPc} ; \mathrm{M}=\mathrm{Co}$ and $\mathrm{Ni}$ ) from DMF on GC electrode. The CVs for the self-assembled monolayers (SAMs) of $4 \alpha-\mathrm{Co}^{\mathrm{II}} \mathrm{TAPc}$ and $4 \alpha-\mathrm{Ni}^{\mathrm{II}} \mathrm{TAPc}$ show two pairs of well-defined redox couple corresponding to metal and ring. Using the $4 \alpha-\mathrm{Co}^{\mathrm{II}} \mathrm{TAPc}$ SAM modified electrode, sensitive and selective detection of L-cysteine was demonstrated. Further, the SAM modified electrode also successfully separates the oxidation potentials of AA and CySH with a peak separation of $320 \mathrm{mV}$.
\end{abstract}

Keywords. Meso-substituted porphyrin; optochemical sensing; $\mathrm{HCl}$ gas; 1,8,15,22-tetraaminometallophthalocyanine; L-cysteine.

\section{Introduction}

Porphyrin and its derivatives are very stable in nature and have strong absorption characteristics in the region of 350 to $750 \mathrm{~nm} .{ }^{1,2}$ The appearance of strong Soret and $\mathrm{Q}$ bands of porphyrins in the visible region encourage the researchers to design these dyes for the fabrication of optochemical sensors. Considering the well-understood ability of heme to bind gases like $\mathrm{NO}, \mathrm{CO}_{2}$, and $\mathrm{O}_{2}$, porphyrins would indeed seem a suitable choice for the detection of gaseous species. ${ }^{3}$ Research in this area has focused on incorporation of synthetic porphyrins and metalloporphyrins into different matrixes including polymers, glasses, and Langmuir-Blodgett (LB) films. ${ }^{4-11}$ Since porphyrin derivatives are very stable both thermally and chemically, they have attracted much interest as potential materials for integration into optochemical gas sensors. Hydrogen chloride $(\mathrm{HCl})$ gas is the source for acid rain as well as a work place hazard with a short term exposure limit of $5 \mathrm{ppm}$ and therefore sensing and standardization of its level in the atmosphere are very important. The concentration of $\mathrm{HCl}$ in the environment is now strictly regulated in many countries owing to its hazardous nature. Porphyrin, when deposited as a thin film, interacts with inorganic

*For correspondence gases such as $\mathrm{H}_{2} \mathrm{~S}, \mathrm{HCl}, \mathrm{Cl}_{2}$, and $\mathrm{NH}_{3}$ by absorption on to the sensing layer. ${ }^{3}$ The previously reported sensors are mainly based on the incorporation of porphyrin into hydrophobic membrane, ethyl cellulose, sol-gel and polymer composite materials. ${ }^{4-11}$ Although many reports were available in the literature for the optochemical detection of $\mathrm{HCl}$ gas, fabrication of a solid state sensor for $\mathrm{HCl}$ gas with high stability, sensitivity and selectivity is still one of the challenging tasks for the researchers. In this paper, we have employed a very simple procedure to fabricate a solid state sensor by coating the porphyrin derivatives on glass slide and examined optochemical sensing of $\mathrm{HCl}$ gas. We have synthesized meso-tetramesitylporphyrin (MTMP), meso-tetraphenylporphyrin (MTPP) and meso-tetrakis(4-nitrophenyl)porphyrin (MTNP) (scheme 1) and studied their $\mathrm{HCl}$ gas sensing properties after coated on glass slides.

Phthalocyanines (Pcs) are macrocyclic $18-\pi$ electron aromatic compounds with four isoindoline units joined by four azo nitrogens. This structure is very similar to the naturally occurring porphyrins. Thus, it is interesting to fabricate thin films of both porphyrin and phthalocyanine on solid substrates and examine their optical and electrochemical properties. Replacement of four methine groups in the meso position of porphyrin by four azo nitrogens make Pcs more stable towards heat 


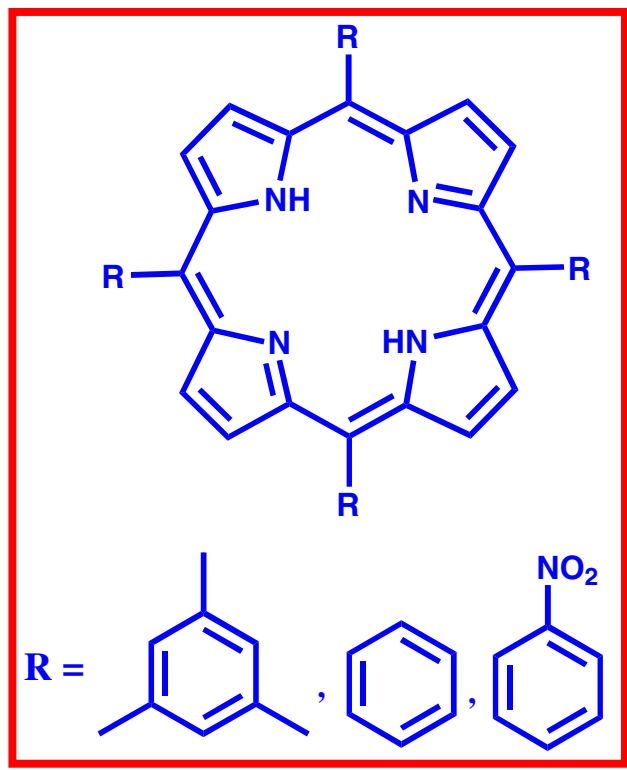

(a)

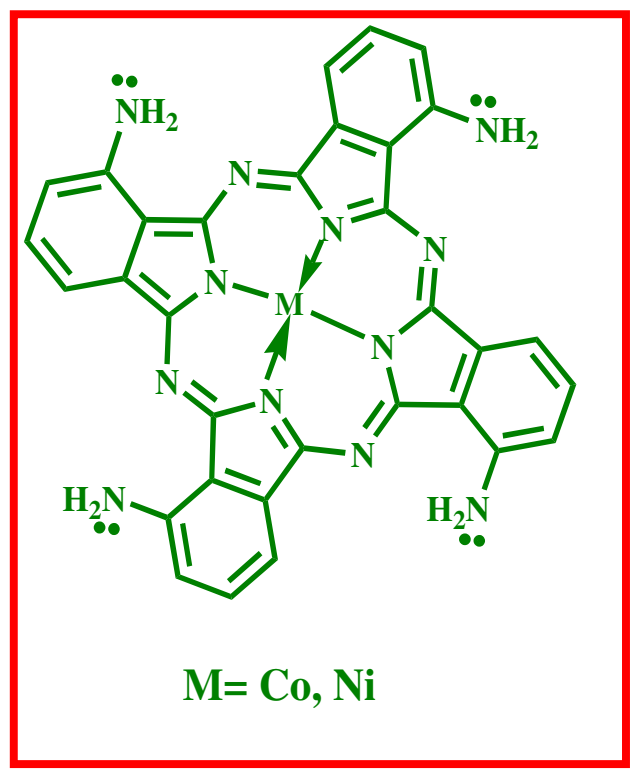

(b)

Scheme 1. Structures of (a) porphyrin derivatives and (b) 1,8,15,22-tetraaminometallophthalocyanine.

and light. ${ }^{12}$ Further, substitution of the porphyrin ring with four benzene rings gives greater delocalization of $\pi$ electron density in Pcs. As a result of this extended delocalization, the electronic spectrum of Pcs show a bathochromic shift in the absorption maximum $\left(\lambda_{\max }\right)$ relative to that of porphyrins. ${ }^{13}$ The Pcs have greater structural flexibility and hence internal hydrogens in the Pc inner core can be replaced by most of the metals in the periodic table to yield metallophthalocyanines (MPcs). The high thermal and chemical stabilities of MPcs lead to the technological applications in the fields of chemical sensors, ${ }^{14,15}$ liquid crystals, ${ }^{16,17}$ field effect transistors, ${ }^{18}$ electrochromic devices, ${ }^{19,20}$ optical data storage systems ${ }^{21,22}$ and photodynamic therapy. ${ }^{23,24}$ Fabrication of thin films of MPcs on solid substrates has been received great interest to the researchers because of their extensive applications in photovoltaic cells, molecular electronics, optical data storage systems, electrochemical and optochemical sensors and electrochromic devices. Since most of the applications of Pcs were mainly based on thin films formed on solid substrates it is very important to find a suitable method to prepare an ordered film on solid substrates with high stability. Various methods have been used for the fabrication of MPc thin films which include direct deposition of MPc solution on electrode surface via casting, ${ }^{25}$ electropolymerization, ${ }^{26}$ self-assembly (SA), ${ }^{27}$ spin coating ${ }^{28}$ and vapour deposition. ${ }^{29}$ Among these methods, modification of electrode surface by SA method using MPcs is one of the elegant methods because highly ordered films can be prepared easily on the electrode surface by this method. Further, thin films of MPcs prepared by this method yields reproducible results and much stable for long term usage. ${ }^{30}$ The self-assembled monolayer (SAM) of Pcs on different substrates was achieved by tethering the Pc with carboxylic acid, trichlorosilyl, and thiol or thioether groups. One of the important issues for these Pcs is the tedious procedure involved in the synthesis and also ends up with low yield. Further, the organosulphur functionalized Pcs are unstable in atmospheric conditions. Recently, it has been shown that Pcs tethered with amine functional groups can also form SAM on Ag and Au substrates. However, Au and Ag electrodes used for the SAM formation have limited potential window for electrocatalytic applications. Thus, in the present study, we have investigated the selfassembly of amine functionalized MPcs $(1,8,15,22-$ tetraaminometallophthalocyanine ( $4 \alpha$-MTAPc; $\mathrm{M}=\mathrm{Co}$, $\mathrm{Ni}$; scheme 1) on glassy carbon (GC) electrode. Further, the SAM of $4 \alpha-\mathrm{Co}^{\mathrm{II}} \mathrm{TAPc}$ was successfully used for the determination of L-cysteine.

\section{Experimental}

\subsection{Chemicals}

L-cysteine ( $\mathrm{CySH})$ and ascorbic acid (AA) were purchased from Aldrich and were used as received. All other chemicals used in this investigation were of analytical grade and were used as received. Deionized water was prepared by double distillation with alkaline 
$\mathrm{KMnO}_{4}$. Acetate buffer solution was prepared using sodium acetate and acetic acid. meso-tetramesitylporphyrin (MTMP), meso-tetraphenylporphyrin (MTPP) and mesotetrakis-(4-nitrophenyl)porphyrin (MTNP) MTMP were synthesized according to the reported procedure. ${ }^{31}$

\subsection{Fabrication of solid state sensor}

The solid state sensor for $\mathrm{HCl}$ gas detection was fabricated by depositing a thin film of a porphyrin on cleaned glass slide $(0.8 \mathrm{~mm} \times 300 \mathrm{~mm})$ using dip coating method. Clean glass slide was immersed in the $0.01 \mathrm{mM}$ MTMP dissolved in chloroform at the rate of $12 \mathrm{~cm} / \mathrm{min}$ and dried at room temperature under nitrogen atmosphere. A home-made pulsed generator with a stepper at a withdrawal speed of $12 \mathrm{~cm} / \mathrm{min}$ was used to deposit a thin film of porphyrin on glass slide. The same procedure was followed for sensor fabrication using MTPP and MTNP. The porphyrin deposited glass slide was dried at room temperature under nitrogen atmosphere for $10 \mathrm{~min}$. Standard dry $\mathrm{HCl}$ gas (19 ppm) diluted with nitrogen was used and the concentration of $\mathrm{HCl}$ gas was controlled by mixing the standard gas with nitrogen. Mass flow controller was used to mix the desired amount of $\mathrm{HCl}$ gas with dry nitrogen. All measurements were performed at room temperature.

\subsection{Self-assembly of $4 \alpha$-MTAPc on GC surface}

1,8,15,22-Tetraaminophthalocyanatocobalt(II) and $\mathrm{Ni}$ (II) were synthesized based on the reported procedure. $^{32}$ The SAM of $4 \alpha$-MTAPc was formed by soaking the cleaned GC electrode in completely deaerated dimethylformamide (DMF) containing $1 \mathrm{mM} 4 \alpha$ MTAPc at different time intervals. The electrode was then removed from the solution and repeatedly washed with DMF. The charge under the anodic wave corresponding to $\mathrm{Co}$ (II) oxidation was used to calculate the surface coverage without subtracting the electrode roughness factor.

\subsection{Instrumentation}

Perkin Elmer Lambda 35 spectrophotometer was used to record the UV-vis absorption spectra. Electrochemical measurements were performed in a conventional two compartment three electrode cell with a mirror polished glassy carbon (GC) as a working electrode. $\mathrm{Pt}$ wire as counter electrode and $\mathrm{KCl}$ saturated $\mathrm{Ag} / \mathrm{AgCl}$ as reference electrode. The electrochemical measurements were carried out with CHI model 643B (Austin, TX, USA) Electrochemical Workstation. Raman spectra were recorded using a Renishaw Raman microscope, with the $514 \mathrm{~nm} \mathrm{Ar}+$ ion laser for excitation. All the electrochemical measurements were carried out under nitrogen atmosphere at room temperature. AFM images were obtained using MultiMode V scanning Probe Microscope for MTMP coated glass plates.

\section{Results and discussion}

\subsection{Characterization of the solid state sensor}

The UV-vis spectrum obtained for MTMP deposited glass slide shows a more intense absorbance for Soret band at $438 \mathrm{~nm}$ along with less intense peaks at $521,549,595$, and $650 \mathrm{~nm}$ corresponding to Q bands (figure 1 (curve a)). The observed characteristic spectral bands of MTMP deposited glass slide clearly indicate that MTMP was adsorbed on the glass slide. In contrast to MTMP in dichloromethane (figure S1; supporting information), a $16 \mathrm{~nm}$ red shift in the Soret band was observed for MTMP deposited glass slide. This may be attributed to the aggregation of the porphyrin molecules in solid state. ${ }^{33}$ When the MTMP deposited glass slide was exposed to $\mathrm{HCl}$ vapour, not only the Soret band was shifted from 438 to $453 \mathrm{~nm}$ but also intensities were found to increase at 453 and $650 \mathrm{~nm}$ (curve b). The observed $15 \mathrm{~nm}$ shift in the Soret band with an increase in intensities at both 453 and $650 \mathrm{~nm}$ was attributed to the formation of J-aggregates. Further, the aggregation of MTMP molecules upon protonation was confirmed

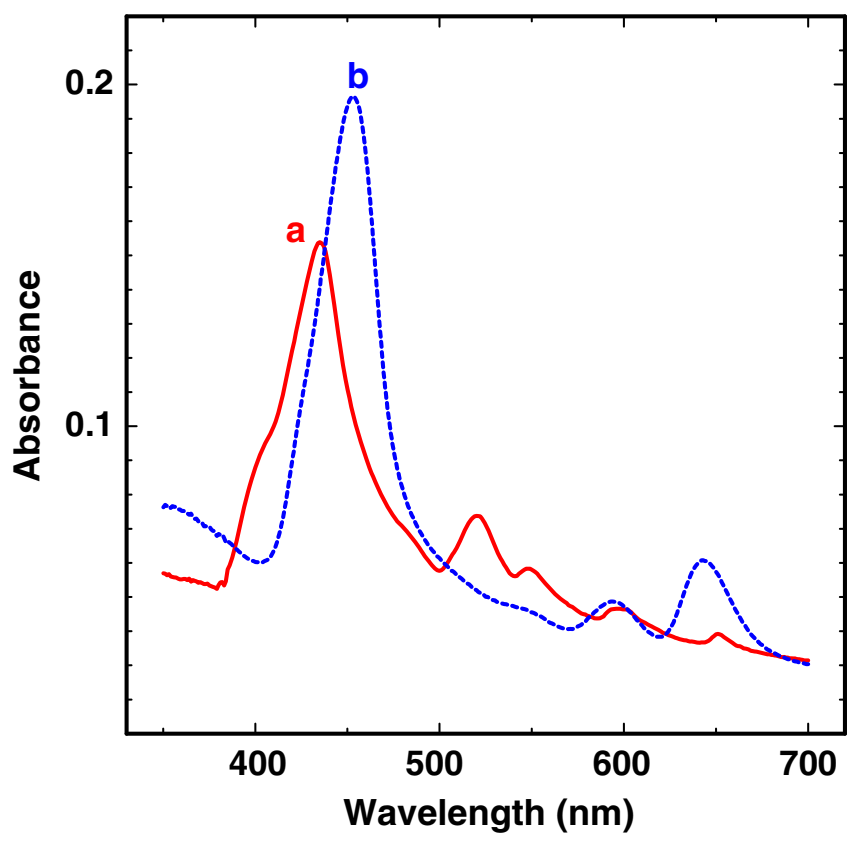

Figure 1. Absorption spectra obtained for MTMP film coated on glass slide (a) before and (b) after exposed to $\mathrm{HCl}$ vapour. 
by AFM studies. Figure 2a shows the tapping mode 2D AFM image of the glass slide coated with MTMP. The thickness of the thin film was found to be $10 \mathrm{~nm}$ (figure 2b). When this film was exposed to $\mathrm{HCl}$ vapour for a minute, aggregated structure was obtained (figure $2 \mathrm{c}$ ). The $3 \mathrm{D}$ view (figure $2 \mathrm{~d}$ ) indicated that the nanostructures of MTMP aggregates were grown vertically in contrast to MTMP thin film. Rearranged BeerLambert equation was used to calculate the surface density $\left(d_{\text {surf }}\right)$ of the porphyrin molecules. ${ }^{34}$

$$
d_{\text {surf }}=A \times \varepsilon^{-1}
$$

where $A$ is the Soret band absorbance of MTMP and $\varepsilon$ is molar extinction coefficient. The surface density of MTMP molecules in MTMP film was found to be $6.7 \times$ $10^{-7} \mathrm{~mol} \mathrm{~cm}^{-2}$.

\subsection{Detection of $\mathrm{HCl}$ gas}

To obtain quantitative information about the sensing properties of solid state sensor, UV-vis spectra were recorded and the corresponding responses for successive exposure of $\mathrm{HCl}$ vapour to solid state sensor are shown in figure 3 . As the exposure time of $\mathrm{HCl}$ increases, the absorbance of Soret band at $452 \mathrm{~nm}$ increases significantly in addition to other bands. The absorbance changes of Soret band at $452 \mathrm{~nm}$ were monitored with respect to the concentration of exposed $\mathrm{HCl}$ gas. As shown in figure 3, the solid state sensor shows a sharp increase in the absorbance after exposed to $0.4 \mathrm{ppm} \mathrm{HCl}$ gas which implies the sensing capability of solid state sensor towards $\mathrm{HCl}$ gas.

Exposure of the sensor to $\mathrm{HCl}$ gas leads to the conversion of MTMP into PMTMP and thus the intensity of Soret band at $452 \mathrm{~nm}$ sharply increases (figure 4 ). When an inert gas $\left(\mathrm{N}_{2}\right)$ was passed after reaching the equilibrium state, the Soret band intensity at $452 \mathrm{~nm}$ started to decrease and attained the original intensity as observed for MTMP suggesting that PMTMP was reverted to MTMP. A set of four successive $\mathrm{HCl}$ exposures to solid state sensor was carried out in the range of $0.4-0.1 \mathrm{ppm}$ (figure 4). The sensor showed good response to even at the concentration of $0.1 \mathrm{ppm} \mathrm{HCl}$ gas with good

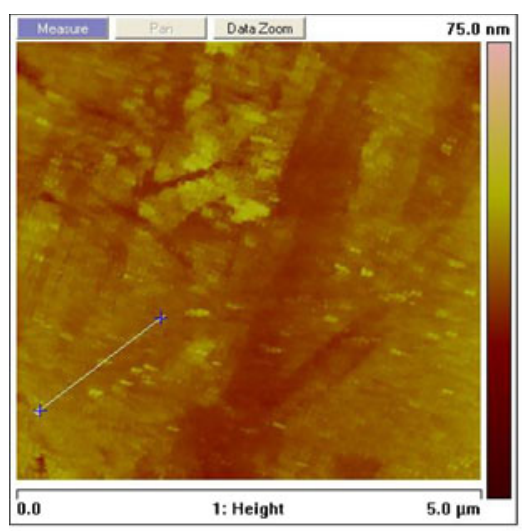

(a)

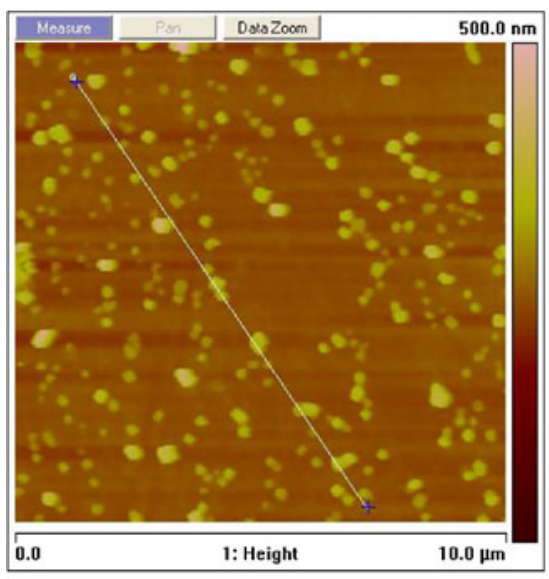

(c)
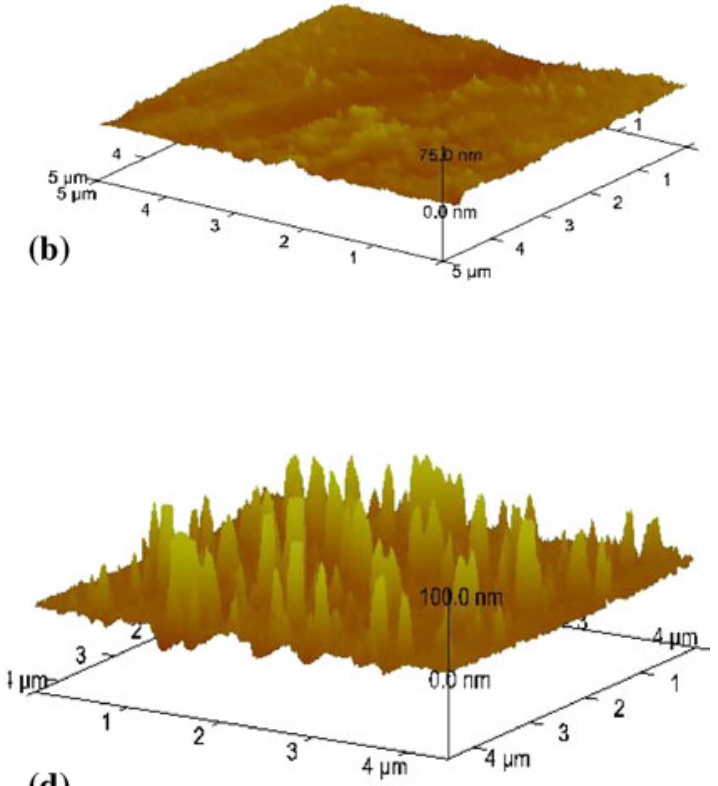

(d)

Figure 2. Tapping mode AFM images of the glass slide coated with MTMP before (a) 2D and (b) 3D views and (c) 2D and (d) 3D views after exposed to $\mathrm{HCl}$ vapour. 


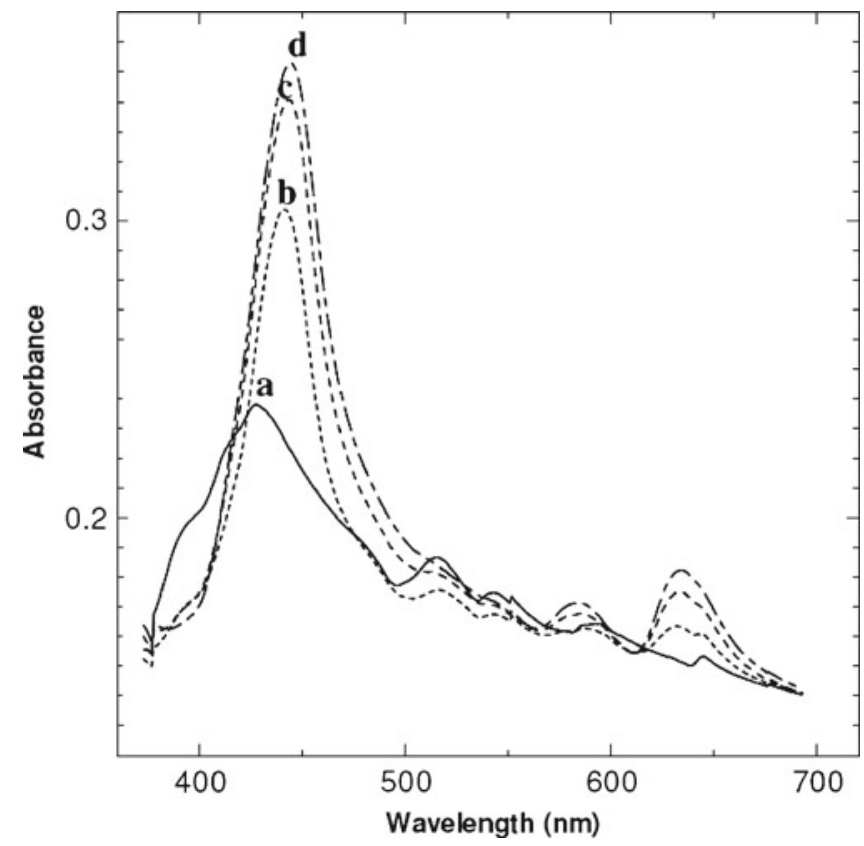

Figure 3. Absorption spectra of MTMP deposited glass plate before (a) and after (b) 5, (c) 120, and (d) $180 \mathrm{~s}$ exposure to $0.4 \mathrm{ppm} \mathrm{HCl}$ vapour.

reversibility. Absorbance variation $(\Delta A)$ was obtained from the differences between the absorbance intensities of the MTMP thin film at $452 \mathrm{~nm}$ before and after exposure to different $\mathrm{HCl}$ concentrations. ${ }^{35}$ To obtain the calibration curve, we have plotted the concentrations of $\mathrm{HCl}$ against the $(\Delta A)$. As the concentration of

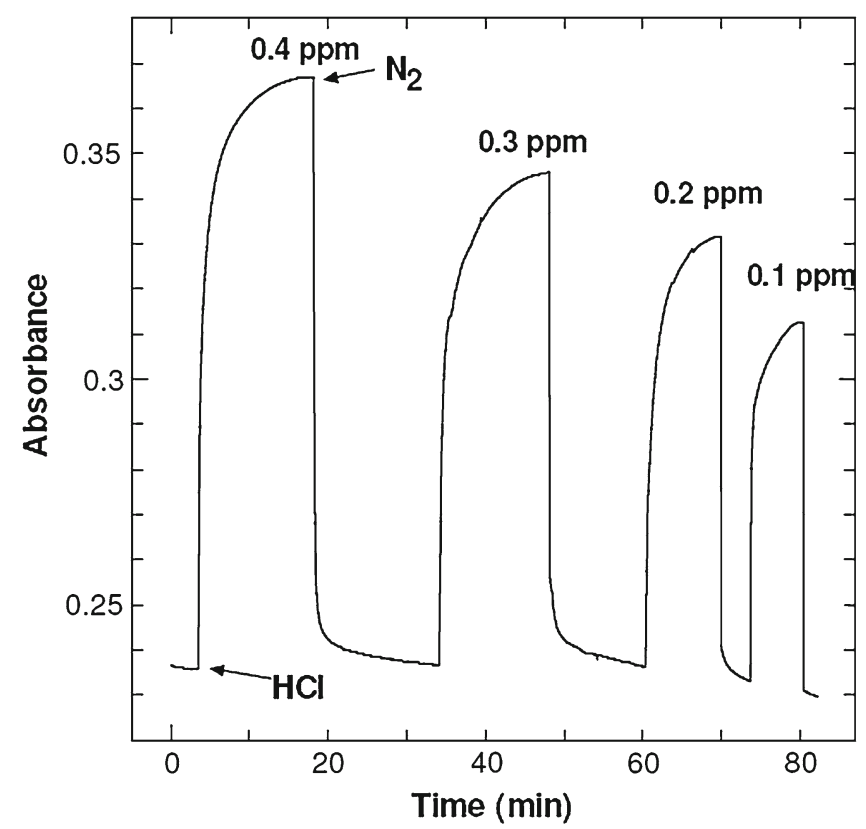

Figure 4. Absorption response and recovery of MTMP deposited glass plate for successive exposures to $\mathrm{HCl}$ gas in the range of $0.4-0.1 \mathrm{ppm}$.
$\mathrm{HCl}$ gas increases, the absorbance of the Soret band also increases yielding the following equation

$$
\begin{aligned}
\text { Absorbance }= & 0.1692( \pm 0.0118) \\
& \times \text { concentration } \\
& +0.06135( \pm 0.0032)
\end{aligned}
$$

(Number of data $=4$; correlation coefficient $=0.9959)$. The complete reversibility of $0.4 \mathrm{ppm} \mathrm{HCl}$ gas exposed sensor was attained after passing $\mathrm{N}_{2}$ for $16 \mathrm{~min}$, which indicates that the sensor is fully reversible but the rate of reversal is markedly slower than the rate of the response. The detection limit of the solid state sensor found to be $0.03 \mathrm{ppm}$. The detection limit was measured by analysing standards that are zero in concentration then measuring the standard deviation of the measurements. In order to reduce the probability of a false nondetection, the standard deviation is then multiplied by the factor 3.0. ${ }^{36}$

\subsection{Optochemical sensing of $\mathrm{HCl}$ gas using MTPP deposited glass slide}

The $\mathrm{HCl}$ sensing properties of MTPP film was studied similar to MTMP. The MTPP was coated on a glass slide and used for $\mathrm{HCl}$ sensing. The protonation of MTPP (figure 5) leads to $15 \mathrm{~nm}$ red shift of Soret band. The deprotonation of the porphyrin was checked with flushing of $\mathrm{N}_{2}$ gas and found that the reversibility of

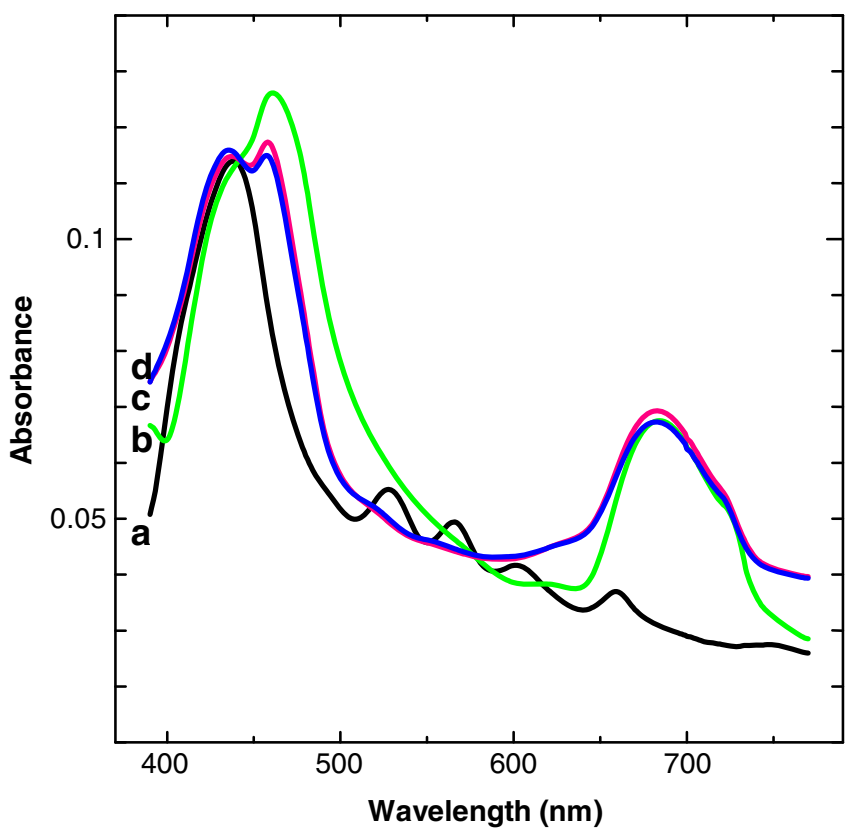

Figure 5. Absorption spectra of MTPP deposited glass plate (a) before and (b) after $180 \mathrm{~s}$ exposure to $0.4 \mathrm{ppm} \mathrm{HCl}$ vapour. The same film after flushing with nitrogen gas for (c) 1200 and (d) $3200 \mathrm{~s}$. 
MTPP is very poor (figure 5). The reversibility was not observed even after $1 \mathrm{~h}$ of flushing out with $\mathrm{N}_{2}$ gas (figure 6a). The absorption changes of MTPP coated glass slide towards the $\mathrm{HCl}$ gas is shown in figure $6 \mathrm{a}$. After the introduction of $\mathrm{HCl}$ gas, the absorption at $458 \mathrm{~nm}$ sharply increased. After reaching the steady state, the $\mathrm{HCl}$ gas was cut off and the $\mathrm{N}_{2}$ flush out was introduced. The decrease in absorption was not sharp and regular. The complete reversibility was not achieved even after $45 \mathrm{~min}$. This indicated that the MTPP coated film can not be used as $\mathrm{HCl}$ sensor. The poor reversibility of the sensor may be due to the absence of bulky group like mesityl at meso positions.

\subsection{Optochemical sensing of $\mathrm{HCl}$ gas using MTNP deposited glass slide}

Similar to MTPP, MTNP film was also screened for the $\mathrm{HCl}$ sensing properties. The MTNP was coated on a glass slide and used for $\mathrm{HCl}$ sensing. The protonation of MTNP (figure S2 in the supporting information) leads to $23 \mathrm{~nm}$ red shift of Soret band. The protonation of MTNP by $\mathrm{HCl}$ gas was not resulted in a significant change in the absorption of the Q band at $670 \mathrm{~nm}$ as in the case of MTMP or MTPP (figure S2). The absorption changes of MTNP coated glass slide towards $\mathrm{HCl}$ gas is shown in figure $6 \mathrm{~b}$. After the introduction of $\mathrm{HCl}$ gas, the absorption at $461 \mathrm{~nm}$ sharply increased. After reaching the steady state, the $\mathrm{HCl}$ gas was cut-off and the $\mathrm{N}_{2}$ gas flush out was introduced. The decrease in absorption was not sharp and complete reversibility was not observed even after $45 \mathrm{~min}$. The observed results indicated that MTNP coated glass slide can not be used $\mathrm{HCl}$ sensing due to the poor reproducibility. The poor reversibility of the MTNP coated glass slide may be due to the flexibility of porphyrin ring in the absence of bulky group like mesityl at meso positions in addition to the different organization of the MTNP molecules on the solid surface.

\subsection{Adsorption of $4 \alpha-C o^{I I} T A P c$ on $G C$ electrode}

The SA of $4 \alpha-\mathrm{Co}^{\mathrm{II}} \mathrm{TAPc}$ on GC electrode was followed by cyclic voltammetry (CV). CVs obtained for $4 \alpha$-Co ${ }^{\text {II TAPc }}$ adsorbed on GC electrode at different immersion time intervals in DMF containing $1 \mathrm{mM} 4 \alpha$ $\mathrm{Co}^{\mathrm{II}} \mathrm{TAPc}$ at a scan rate of $0.1 \mathrm{~V} \mathrm{~s}^{-1}$ in $0.1 \mathrm{M} \mathrm{H}_{2} \mathrm{SO}_{4}$ are shown in figure $\mathrm{S} 3$. The $4 \alpha-\mathrm{Co}^{\mathrm{II}} \mathrm{TAPc}$ adsorbed on GC electrode for $10 \mathrm{~s}$ shows a well-defined two pairs of redox peaks (curve a). The $E_{1 / 2}$ of $0.36 \mathrm{~V}$ with a peak separation of $0.36 \mathrm{~V}$ was observed for a redox peak appeared at less positive potential. This redox wave was assigned to $\mathrm{Co}^{\mathrm{III}} / \mathrm{Co}^{\mathrm{II}}$ redox couple based on the earlier reports. ${ }^{32,37,38}$ On the other hand, the redox peak appeared at more positive potential was assigned to $\mathrm{Pc}$ ring based redox couple i.e., $\mathrm{Co}^{\mathrm{III}} \mathrm{Pc}^{1-} / \mathrm{Co}^{\mathrm{III}} \mathrm{Pc}^{2-}$. As the adsorption time of GC electrode in $4 \alpha-\mathrm{Co}^{\mathrm{II}} \mathrm{TAPc}$ solution increased, the charge under the redox peaks were gradually increased while the redox peak potentials were almost unchanged. This indicated that more and more molecules were adsorbed on the GC electrode as the adsorption time was increased. The charge under the redox peaks increased up to $3 \mathrm{~h}$ immersion time and after that it remained constant indicating that $4 \alpha-\mathrm{Co}^{\mathrm{II}} \mathrm{TAPc}$ required $3 \mathrm{~h}$ time to attain the saturation coverage.

Further, it was noted from the CVs shown in figure S3 that as the immersion time increased, the capacitance current also increased along with Faradaic charge. Generally, the capacitance current of the double-layer
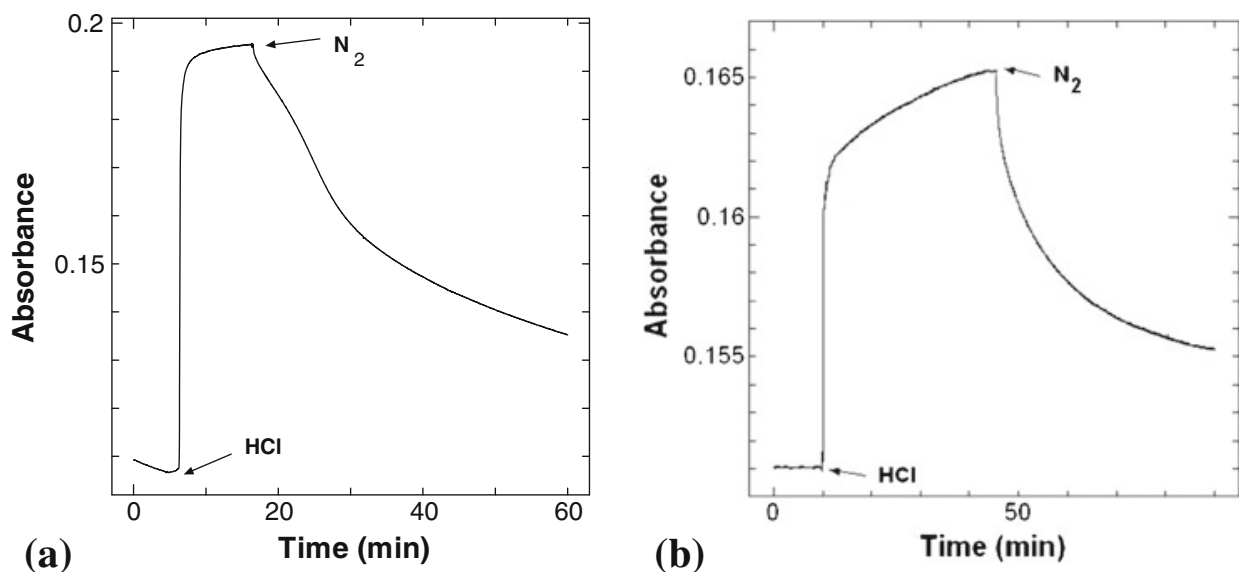

Figure 6. (a) Absorption changes at $458 \mathrm{~nm}$ of MTPP deposited glass plate exposed to $0.4 \mathrm{ppm} \mathrm{HCl}$ vapour. (b) Absorption changes at $461 \mathrm{~nm}$ of MTNP deposited glass plate exposed to $0.4 \mathrm{ppm} \mathrm{HCl}$ vapour. 
increases as the dielectric behaviour of terminal group substituted in the SAM increases. ${ }^{39}$ Raman spectral studies confirmed that all the four amino groups of $4 \alpha$ $\mathrm{Co}^{\mathrm{II}} \mathrm{TAPc}$ were not involved in the chemisorption on carbon surface. ${ }^{32,38}$ Hence, as the adsorption of $4 \alpha-$ $\mathrm{Co}^{\mathrm{II}} \mathrm{TAPc}$ on $\mathrm{GC}$ electrode was increased, the population of free amino groups was also increased which in turn leads to the increase in capacitance current. However, the peak potentials and shape of the $\mathrm{CV}$ remained same for several continuous potential cycles demonstrating that the monolayer was highly stable. The surface coverage $(\Gamma)$ was calculated for $4 \alpha-\mathrm{Co}^{\mathrm{II}} \mathrm{TAPc}$ adsorbed on GC electrode at different time intervals by integrating the charge under the anodic wave corresponding to $\mathrm{Co}^{\mathrm{II}}$ to $\mathrm{Co}^{\mathrm{III}}$. It was found that surface coverage value increased when the adsorption time of $4 \alpha-\mathrm{Co}^{\mathrm{II}} \mathrm{TAPc}$ on GC electrode increased and saturation coverage $\left(\Gamma_{\mathrm{s}}\right)$ of $2.37 \times 10^{-10} \mathrm{~mol} \mathrm{~cm}^{-2}$ was reached after $3 \mathrm{~h}$. Surprisingly, $45 \%$ of the surface coverage $\left(1.07 \times 10^{-10} \mathrm{~mol} \mathrm{~cm}^{-2}\right)$ of $4 \alpha-\mathrm{Co}^{\mathrm{II}} \mathrm{TAPc}$ on GC surface was achieved within $10 \mathrm{~s}$, indicating that the adsorption of $4 \alpha-\mathrm{Co}^{\mathrm{II}} \mathrm{TAPc}$ on GC electrode is very fast. According to previous reports, the CoPc molecule lying flat on the surface with an umbrella configuration will occupy an area close to $200 \AA^{2}$ with a surface coverage of approximately $1 \times 10^{-10} \mathrm{~mol} \mathrm{~cm}{ }^{-2} \cdot{ }^{40,41}$ However, in the present case, the estimated surface coverage for $4 \alpha-\mathrm{Co}^{\mathrm{II}} \mathrm{TAPc}$ was nearly 2.5 times higher than that of perfectly flat oriented $\mathrm{CoPc}$. There are two possible reasons for the observed higher coverage of $4 \alpha-\mathrm{Co}^{\mathrm{II}} \mathrm{TAPc}$ on $\mathrm{GC}$ electrode. One reason is surface roughness of the GC electrode and due to this it is likely that more number of $4 \alpha-\mathrm{Co}^{\mathrm{II}} \mathrm{TAPc}$ molecules was adsorbed on the GC electrode. ${ }^{42}$ The second reason is that $4 \alpha-\mathrm{Co}^{\mathrm{II}}$ TAPc molecules did not adopt perfect flat orientation on GC surface and this was confirmed from Raman spectral studies. $^{38}$

\subsection{Electrochemical behaviour of $4 \alpha-C o^{I I} T A P c S A M$ on GC electrode}

Figure $7 \mathrm{a}$ shows the CVs of $4 \alpha-\mathrm{Co}^{\mathrm{II}} \mathrm{TAPc}$ SAM on GC electrode in $0.1 \mathrm{M} \mathrm{H}_{2} \mathrm{SO}_{4}$ at different scan rates for both metal and Pc ring based redox couples. The $\mathrm{CVs}$ were consistent in all respects with that expected for an electrochemically reversible reaction involving a surface confined species. For example, the $\Delta E$ values were very small $(45 \mathrm{mV})$ and the peak current varied linearly with $v$ in the range of $0.1-1.0 \mathrm{Vs}^{-1}$ (inset of figure 7a) confirming that the observed redox reaction was due to surface confined species. Further, the $\mathrm{CV}$ was stable upon repeated potential cycling. The stability of the SAM of $4 \alpha-\mathrm{Co}^{\mathrm{II}} \mathrm{TAPc}$ on GC electrode was checked by exposing the modified electrodes in the atmospheric air for a month. Even after a month, the electrodes showed the CV similar to that of electrodes not exposed to air (figure not shown). Further, these electrodes were also showed stable $\mathrm{CV}$ after 5 min sonication. Such an excellent physical and chemical stability is owing to the strong chemical interaction with the underlying electrodes and not because of simple physical interaction.

Figure $7 \mathrm{~b}$ shows the $\mathrm{CV}$ s obtained for the SAM of $4 \alpha-\mathrm{Ni}^{\mathrm{II}} \mathrm{TAPc}$ on GC electrode in $0.1 \mathrm{M} \mathrm{H}_{2} \mathrm{SO}_{4}$ at different scan rates. SAM of $4 \alpha-\mathrm{Ni}^{\mathrm{II}} \mathrm{TAPc}$ showed two pairs of well-defined reversible redox peak (curve a). The peak labelled as I has an $E_{1 / 2}$ and $\Delta E$ of $0.37 \mathrm{~V}$ and $62 \mathrm{mV}$, respectively and the peak labelled as II has $E_{1 / 2}$ and $\Delta E$ of $0.63 \mathrm{~V}$ and $73 \mathrm{mV}$, respectively. Based on the earlier reports, ${ }^{26}$ the redox wave I was
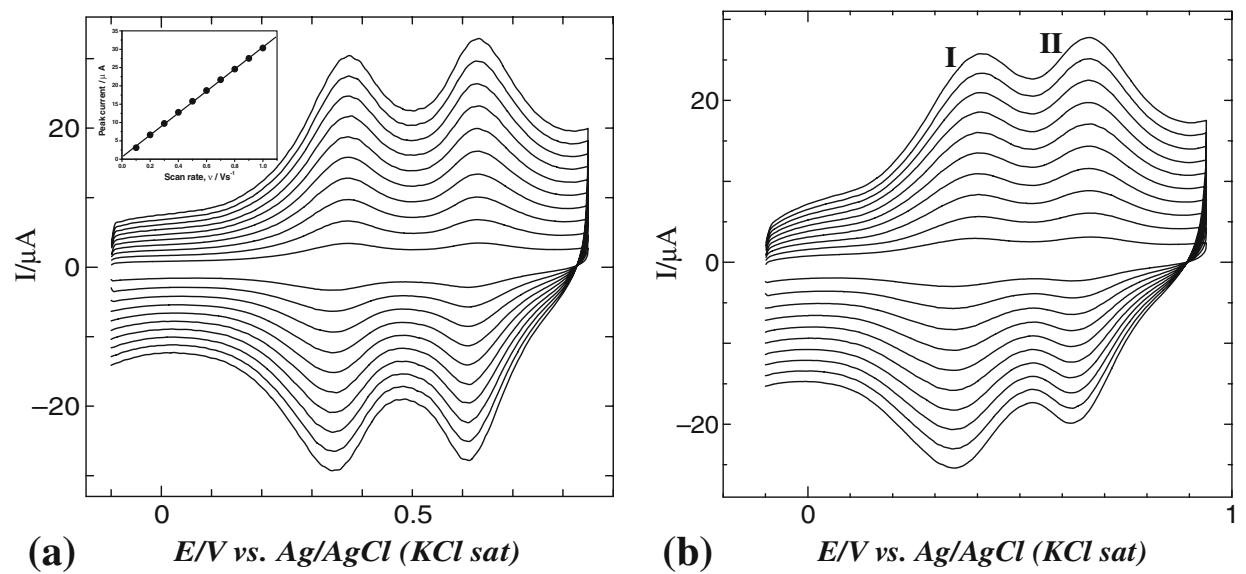

Figure 7. (a) CVs of SAM of $4 \alpha-\mathrm{Co}^{\mathrm{II}} \mathrm{TAPc}$ on $\mathrm{GC}$ electrode in $0.1 \mathrm{M} \mathrm{H}_{2} \mathrm{SO}_{4}$ at scan rates of $0.1,0.2,0.3,0.4,0.5,0.6,0.7,0.8,0.9$ and $1.0 \mathrm{~V} \mathrm{~s}^{-1}$. (b) $\mathrm{CV}_{\mathrm{s}}$ of self-assembled $4 \alpha-\mathrm{Ni}^{\mathrm{II}}$ TAPc GC electrode in $0.1 \mathrm{M} \mathrm{H}_{2} \mathrm{SO}_{4}$ at scan rates of $0.1,0.2,0.3,0.4,0.5,0.6,0.7$, $0.8,0.9$ and $1.0 \mathrm{~V} \mathrm{~s}^{-1}$. 
assigned to nickel metal centre redox process specifically $\mathrm{Ni}{ }^{\mathrm{III}} / \mathrm{Ni}^{\mathrm{II}}$ and the redox wave II was assigned to $\mathrm{Ni}^{\mathrm{III}} \mathrm{Pc}^{1-} / \mathrm{Ni}^{\mathrm{II}} \mathrm{Pc}^{2-}$. The $\mathrm{CV}$ s were consistent in all respects with that anticipated for an electrochemically reversible reaction involving a surface confined species. For example, the $\Delta E$ values were typically small and the peak current varied linearly with $v$ in the range of $0.1-0.8 \mathrm{~V} \mathrm{~s}^{-1}$ confirming that the observed redox reaction was due to surface confined species.

\subsection{Electrochemical behaviour of L-cysteine at $4 \alpha-C O^{I I} T A P c$ SAM modified GC electrode}

Before examining the electrocatalytic activity of $4 \alpha$ $\mathrm{Co}^{\mathrm{II}} \mathrm{TAPc} \mathrm{SAM}$ modified GC electrode towards $\mathrm{CySH}$, we have examined the electrochemical behaviour of $4 \alpha$-Co ${ }^{\mathrm{II}} \mathrm{TAPc}$ SAM modified electrode in acetate buffer solution. It shows two pairs of well-defined redox peaks for the SAM of $4 \alpha-\mathrm{Co}^{\mathrm{II}} \mathrm{TAPc}$ on GC electrode (figure 8). The redox peak I at less positive potential with an $E_{1 / 2}$ and $\Delta E$ of $0.16 \mathrm{~V}$ and $40 \mathrm{mV}$, respectively due to $\mathrm{Co}{ }^{\text {III }} / \mathrm{Co}^{\mathrm{II}}$ redox couple. On the other hand, the redox peak II at higher positive potential with an $E_{1 / 2}$ and $\Delta E$ of $0.40 \mathrm{~V}$ and $22 \mathrm{mV}$, respectively corresponds to $\mathrm{Co}^{\mathrm{III}} \mathrm{Pc}^{-1} / \mathrm{Co}^{\mathrm{III}} \mathrm{Pc}^{-2} .{ }^{32,38}$ We have examined the electrocatalytic activity of $4 \alpha-\mathrm{Co}^{\mathrm{II}}$ TAPc SAM modified $\mathrm{GC}$ electrode towards $\mathrm{CySH}$ oxidation by varying the surface coverage of the SAM and found that the saturated surface coverage of $2.37 \times 10^{-10} \mathrm{~mol} \mathrm{~cm} \mathrm{~cm}^{-2}$,

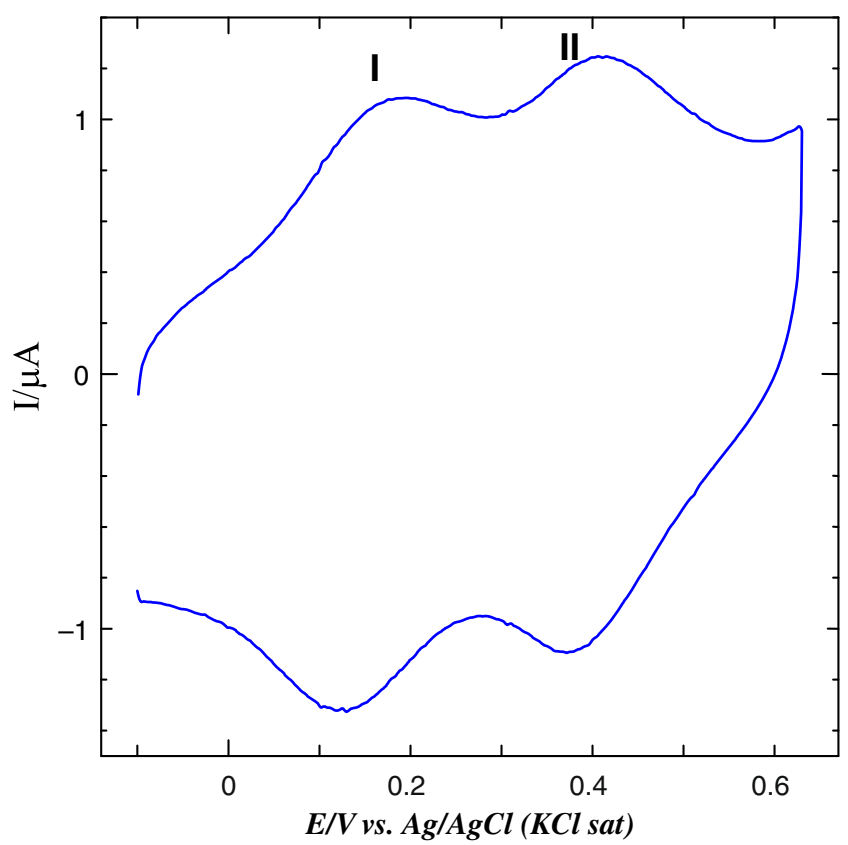

Figure 8. CV obtained for the SAM of $4 \alpha-\mathrm{Co}^{\mathrm{II}} \mathrm{TAPc}$ on $\mathrm{GC}$ electrode in $0.2 \mathrm{M}$ acetate buffer solution ( $\mathrm{pH}$ 5.0) at a scan rate of $0.05 \mathrm{~V} \mathrm{~s}^{-1}$. prepared by $3 \mathrm{~h}$ adsorption of GC electrode in $4 \alpha$ $\mathrm{Co}^{\mathrm{II}} \mathrm{TAPc}$ solution showed higher oxidation current for $\mathrm{CySH}$. We have also studied the $\mathrm{CySH}$ oxidation by varying the $\mathrm{pH}$ and higher current was observed at $\mathrm{pH}$ 5.0. Thus, $\mathrm{CySH}$ oxidation studies are carried out at $\mathrm{pH}$ 5.0 using the $4 \alpha-\mathrm{Co}^{\mathrm{II}} \mathrm{TAPc}$ modified electrode with a saturated surface coverage.

CVs obtained for $0.5 \mathrm{mM} \mathrm{CySH}$ at bare $\mathrm{GC}$ and $4 \alpha-\mathrm{Co}^{\mathrm{II}} \mathrm{TAPc}$ SAM modified GC electrodes in $0.2 \mathrm{M}$ acetate buffer solution ( $\mathrm{pH}$ 5.0) are shown in figure 9. At bare GC electrode, a shoulder wave was obtained for the oxidation of $\mathrm{CySH}$ around $0.65 \mathrm{~V}$ (curve a). Interestingly, the SAM modified electrode exhibited a welldefined oxidation peak at $0.45 \mathrm{~V}$ for $\mathrm{CySH}$ (curve b). At this electrode, nearly seven-fold higher oxidation current and $200 \mathrm{mV}$ less positive potential shift were observed for $\mathrm{CySH}$ when compared to that of bare GC electrode. Now, a doubt may arise whether the observed high current with less positive potential for $\mathrm{CySH}$ is due to the mediation of $\mathrm{Co}^{\mathrm{II}}$ or electrostatic interactions between $\mathrm{CySH}$ and free amine groups of $4 \alpha-\mathrm{Co}^{\mathrm{II}} \mathrm{TAPc}$. In order to clarify this doubt, the electrochemical oxidation of $\mathrm{CySH}$ was carried out at the SAM of free base 1,8,15,22-tetraaminophthalocyanine ( $4 \alpha-\mathrm{H}_{2}$ TAPc) modified GC electrode prepared under identical

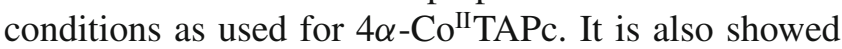
a poor voltammetric response for $\mathrm{CySH}$ oxidation like bare GC electrode (curve c). This result clearly confirmed that $\mathrm{Co}^{\mathrm{II}}$ was mediated the oxidation of $\mathrm{CySH}$.

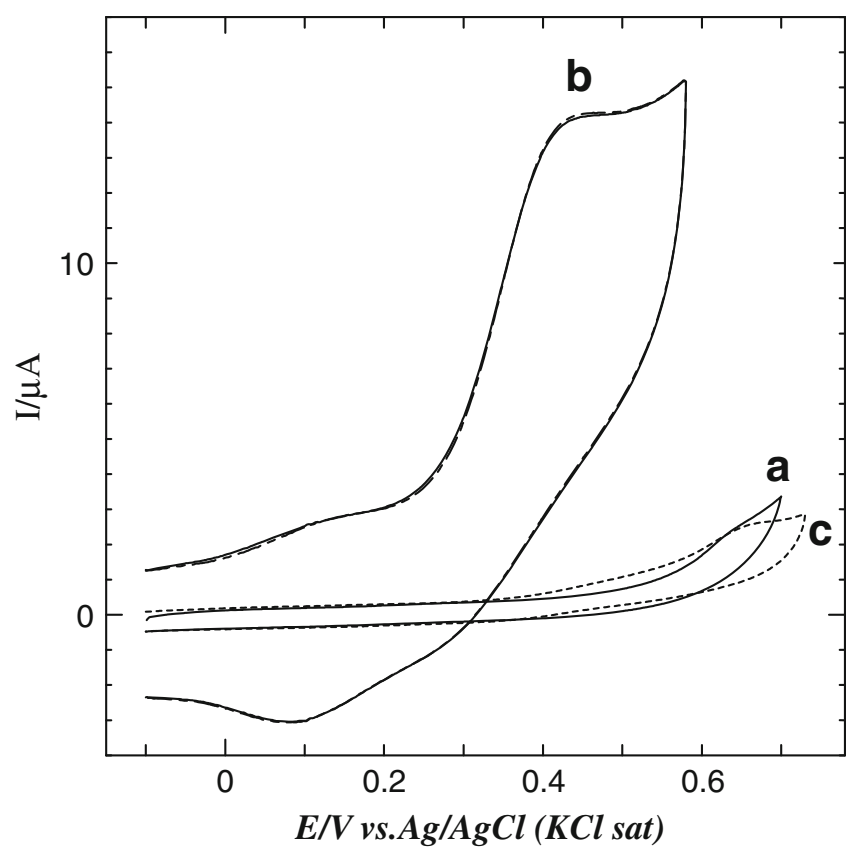

Figure 9. $\mathrm{CVs}$ obtained for $0.5 \mathrm{mM} \mathrm{CySH}$ at (a) bare GC electrode, (b) $4 \alpha-\mathrm{Co}^{\mathrm{II}} \mathrm{TAPc}$ and (c) $4 \alpha-\mathrm{H}_{2}$ TAPc modified GC electrodes in $0.2 \mathrm{M}$ acetate buffer solution ( $\mathrm{pH}$ 5.0) at a scan rate of $0.05 \mathrm{~V} \mathrm{~s}^{-1}$. 

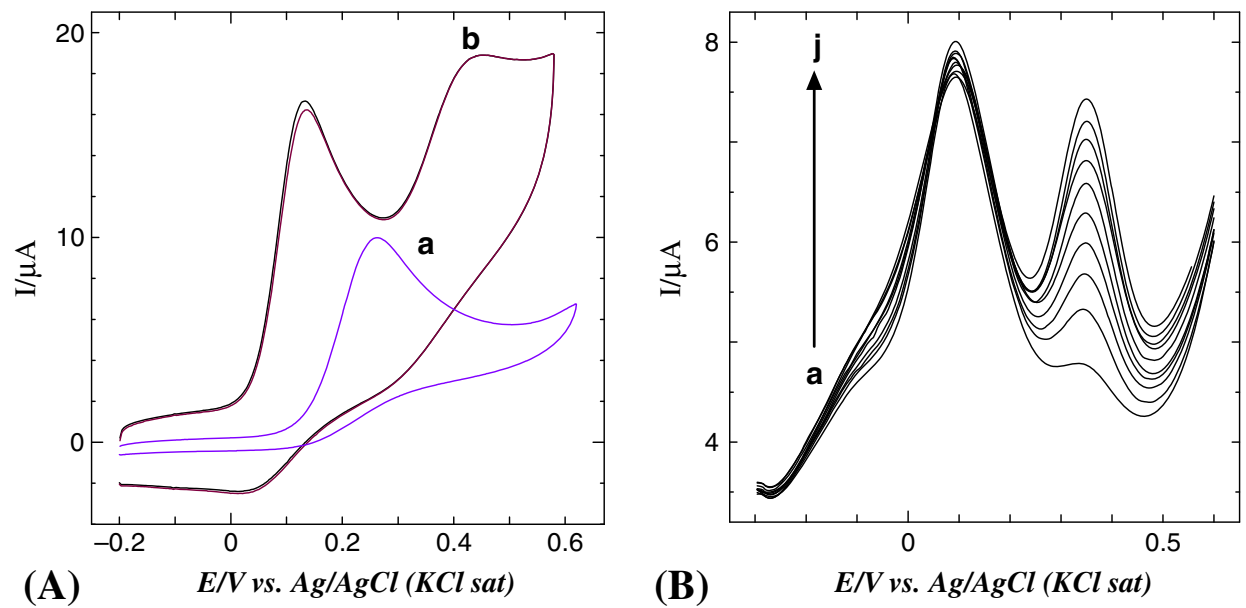

Figure 10. (A) CVs obtained for $0.5 \mathrm{mM}$ each $\mathrm{AA}$ and $\mathrm{CySH}$ at (A) bare and (B) $4 \alpha-$ $\mathrm{Co}^{\mathrm{II}}$ TAPc SAM modified GC electrodes in $0.2 \mathrm{M}$ acetate buffer solution $(\mathrm{pH} 5.0)$ at a scan rate of $0.05 \mathrm{~V} \mathrm{~s}^{-1}$. (B) DPVs obtained for $10 \mu \mathrm{M}$ CySH containing $200 \mu \mathrm{M}$ AA at $4 \alpha-\mathrm{Co}$ II TAPc SAM modified GC electrode in $0.2 \mathrm{M}$ acetate buffer solution (pH 5.0) (curve a). Each addition increases the concentration of CySH by $10 \mu \mathrm{M}(\mathrm{b}-\mathrm{j})$ keeping the concentration of AA as constant.

Based on the results obtained in the present study and previous reports, ${ }^{43,44}$ we are proposing the following mechanism for the oxidation of $\mathrm{CySH}$ at $4 \alpha-\mathrm{Co}^{\mathrm{II}} \mathrm{TAPc}$ SAM modified electrode.

$$
\begin{aligned}
& 4 \alpha-\mathrm{Co}^{\mathrm{II}} \mathrm{TAPc}_{\text {(surface) }} \\
& \rightarrow 4 \alpha-\mathrm{Co}^{\text {III }} \mathrm{TAPc}_{\text {(surface) }}+\mathrm{e}^{-} \\
& 4 \alpha-\mathrm{Co}^{\mathrm{III}} \mathrm{TAPc}_{(\text {surface })}+\mathrm{CySH}_{(\mathrm{aq})} \\
& \rightarrow 4 \alpha-\mathrm{Co}^{\mathrm{II}} \mathrm{TAPc}_{(\text {surface })}+\mathrm{CyS}_{(\mathrm{aq})}+\mathrm{H}_{(\mathrm{aq})}^{+} \\
& 2 \mathrm{CyS}_{(\mathrm{aq})} \rightarrow \mathrm{CySSCy}_{(\mathrm{aq})} \text { (cystine). }
\end{aligned}
$$

The oxidation of $\mathrm{CySH}$ at $4 \alpha-\mathrm{Co}^{\mathrm{II}} \mathrm{TAPc}$ SAM modified electrode was due to two-step process viz., an electrochemical process followed by a chemical reaction. The first step is a one electron electrochemical oxidation of $\mathrm{Co}^{\mathrm{II}}$ to $\mathrm{Co}^{\mathrm{III}}$. The second step is the chemical oxidation of $\mathrm{CySH}$ to cysteine radical by $\mathrm{Co}^{\mathrm{III}}$ species. The generated cysteine radical was highly unstable and instantaneously reacts with another cysteine radical to form a disulphide compound, cystine.

\subsection{Selective determination of $\mathrm{CySH}$ in the presence of $A A$}

AA is one of the major interferences which will encounter in the determination of $\mathrm{CySH}$ in biological fluids. ${ }^{45}$ Therefore, determination of $\mathrm{CySH}$ in the presence of AA is very important for practical applications. Figure 10a shows the CVs obtained for $0.5 \mathrm{mM}$ each of AA and $\mathrm{CySH}$ at bare $\mathrm{GC}$ and $4 \alpha-\mathrm{Co}^{\mathrm{II}} \mathrm{TAPc}$ SAM modified GC electrodes in $0.2 \mathrm{M}$ acetate buffer solution ( $\mathrm{pH}$ 5.0). Bare GC electrode showed only one oxidation peak for the mixture of AA and $\mathrm{CySH}$ (curve a). Interestingly, $4 \alpha$-Co ${ }^{\mathrm{II}} \mathrm{TAPc}$ SAM modified electrode showed well-separated oxidation peaks for AA $(0.13 \mathrm{~V})$ and $\mathrm{CySH}(0.45 \mathrm{~V})$ with a peak separation of $320 \mathrm{mV}$ (curve b) which was more than enough to selectively determine $\mathrm{CySH}$ in the presence of AA. The concentration of AA in the biological fluids is usually higher than the concentration of CySH. Therefore, the determination of $\mathrm{CySH}$ in the presence of higher concentration of AA is very important in the clinical point of view. Figure $10 \mathrm{~b}$ shows the DPV obtained for $10 \mu \mathrm{M}$ of $\mathrm{CySH}$ in the presence of $200 \mu \mathrm{M}$ of AA in $0.2 \mathrm{M}$ acetate buffer solution ( $\mathrm{pH} 5.0)$ at $4 \alpha-\mathrm{Co}^{\mathrm{II}} \mathrm{TAPc}$ SAM modified GC electrode. It showed a clear signal for $\mathrm{CySH}$ oxidation even in the presence of $200 \mu \mathrm{M}$ of AA. This indicated that the detection of low concentration of $\mathrm{CySH}$ is possible in the presence of 20 -fold higher concentration of AA. With the addition of $10 \mu \mathrm{M}$ of $\mathrm{CySH}$ to a solution of $200 \mu \mathrm{M}$ of AA, the oxidation peak current of $\mathrm{CySH}$ was linearly increased with a correlation coefficient of 0.9992 while the peak current of AA remained unchanged. These results clearly revealed that $4 \alpha-\mathrm{Co}^{\mathrm{II}} \mathrm{TAPc}$ SAM modified GC electrode is selective towards $\mathrm{CySH}$ oxidation in the presence of higher concentration of AA.

\section{Concluding remarks}

In the first part of the work, we have adopted a very simple procedure to fabricate the solid state sensor by coating meso-substituted porphyrin derivatives on glass 
slide (solid state sensor) and examined optochemical sensing of $\mathrm{HCl}$ gas. Among the different porphyrin derivatives, meso-tetramesitylporphyrin (MTMP) coated film showed excellent sensitivity towards $\mathrm{HCl}$. The concentration of gaseous $\mathrm{HCl}$ was monitored from the changes in the absorbance of Soret band of PMTMP at $452 \mathrm{~nm}$. The MTMP sensor proposed in this paper has several advantages including ease in preparation and high stability against humid conditions. The lowest detection limit of $0.03 \mathrm{ppm} \mathrm{HCl}$ was obtained for the present solid state sensor. On the other hand, the other porphyrin derivatives, MTPP and MTNP coated glass slides were not suitable for $\mathrm{HCl}$ gas sensing due to their irreversible nature towards protonation and deprotonation.

In the second part of this paper, we have demonstrated the spontaneous self-assembly of 1,8,15,22tetraaminometallophthalocyanine on GC electrode. The CVs for the SAMs of $4 \alpha-\mathrm{Co}^{\mathrm{II}} \mathrm{TAPc}$ and $4 \alpha-\mathrm{Ni}^{\mathrm{II}} \mathrm{TAPc}$ show two pairs of well-defined redox couple corresponding to metal and ring. Further, highly sensitive and selective detection of L-cysteine using the $4 \alpha-\mathrm{Co}^{\mathrm{II}} \mathrm{TAPc}$ SAM modified GC electrode was demonstrated. The $4 \alpha-\mathrm{Co}^{\mathrm{II}} \mathrm{TAPc}$ SAM modified electrode mediates the oxidation of $\mathrm{CySH}$ not only by enhancing its oxidation current but also shifting its potential towards less positive potential. Further, the SAM modified electrode successfully separates the oxidation potentials of AA and $\mathrm{CySH}$ with a peak separation of $320 \mathrm{mV}$. The fabrication of the present modified electrode was simple and no need to preserve it in buffer solution.

\section{Supporting material}

Figures S1-S3 can be seen in www.ias.ac.in/chemsci.

\section{Acknowledgements}

We thank the Department of Science and Technology (DST), New Delhi under Nanomission and Defence Research and Development Organization (DRDO), New Delhi for their generous financial support. We thank Mr. A John Jeevagan, Senior Research Scholar for his help.

\section{References}

1. Khairutdinov R F and Serpone N 1999 J. Phys. Chem. B 103761

2. Baraldi I, Carnevali A, Ponterini G and Vanossi D 1995 J. Mol. Struct. (Theochem) 333121
3. Supriyatno H, Yamashita M, Nakagawa K and Sadaoka Y 2002 Sens. Actuators B: Chem. 85197

4. Luca G, Pollicino G, Romeo A, Scolaro L M 2006 Chem. Mater. 182005

5. Itagaki Y, Deki K, Nakashima S and Sadaoka Y 2006 Sens. Actuators B: Chem. 117302

6. Nakagawa K, Sadaoka Y, Supriyatno H, Kubo A, Tsutsumi C and Tabuchi K 2001 Sens. Actuators B: Chem. 7642

7. Nakagawa K, Kumon K, Tsutsumi C, Tabuchi K, Kitagawa T and Sadaoka Y 2000 Sens. Actuators B: Chem. 65138

8. Supriyatno H, Yamashita M, Nakagawa K and Sadaoka Y 2002 Sens. Actuators B: Chem. 85197

9. Nakagawa K, Kitagawa T and Sadaoka Y 1998 Sens. Actuators B: Chem. 5210

10. Nakagawa K, Tanaka K, Kitagawa $\mathrm{T}$ and Sadaoka $\mathrm{Y}$ 1998 J. Mater. Chem. 81199

11. Itagaki Y, Deki K, Nakashima S I and Sadaoka Y 2005 Sens. Actuators B: Chem. 1393

12. Sobbi A K, Wohrle D and Schlettwein D 1993 J. Chem. Soc. Perkin Trans. II 481

13. Stillman M J and Nyokong T 1989 In: Phthalocyanines: Properties and applications, Leznoff $\mathrm{C} \mathrm{C}$ and Lever A B P (eds), New York: VCH Publishers, Vol. 1

14. Huang J, Virji S, Weiller B H and Kaner R B 2003 J. Am. Chem. Soc. 125125

15. Adhikari B and Majumdar S 2004 Prog. Polym. Sci. 29 699

16. Collins R A and Mohammed K A 1988 J. Phys. D: Appl. Phys. 21154

17. Zagal J, Bedioui F and Dodelet J P (eds) 2006 N4macrocyclic metal complexes, New York: Springer

18. Bao Z, Lovinger A J and Dodabalapur A 2006 Appl. Phys. Lett. 693066

19. Lin C L, Lee C C and Ho K C 2002 J. Electroanal. Chem. 81524

20. Somani P R and Radhakrishnan S 2003 Mater. Chem. Phys. 77117

21. McKeown N B 1998 Phthalocyanine materials: Synthesis, structure and function, Cambridge: Cambridge University Press

22. Gu D, Chen Q, Tang X, Gan F, Shen S, Liu K and Xu H 1995 Opt. Commun. 121125

23. Singerski R, Kalinowski J, Davoli I and Stizza S 1991 Phys. Status Solidi A 125597

24. Bonnett R 1995 Chem. Soc. Rev. 2419

25. Wohrle D, Kaune H, Schumann B and Jaeger N 1986 Macromol. Chem. Phys. 1872947

26. Sivanesan A and John S A 2008 Electrochim. Acta $\mathbf{5 3}$ 6629

27. Simpson T R E, Cook M J, Petty M C, Thorpe S C and Russell D A 1996 Analyst 1211501

28. Cook M J 1996 J. Mater. Chem. 6677

29. Cheng Z H, Gao L, Deng Z T, Jiang N, Liu Q, Shi D X, Du S X, Guo H M and Gao H J 2007 J. Phys. Chem. C. 1119240

30. Kalyuzhny G, Vaskevich A, Ashkenasy G, Shanzer A and Rubinstein I 2000 J. Phys. Chem. B 1048238

31. Lindsey J S and Wagner R W 1989 J. Org. Chem. 54828

32. Sivanesan A and John S A 2008 Langmuir 242186

33. Tonezzer M, Quaranta A, Maggioni G, Carturan S and Della Mea G 2007 Sens. Actuators B: Chem. 122620 
34. Chen H T, Liu B, Wang H T, Xiao Z D, Chen M and Qian D 2007 J Mater. Sci. Eng. C 27639

35. Knyukshto V N, Solovyov K N and Egorova G D 1998 Biospectroscopy 4121

36. Christian G D 2004 Analytical chemistry, sixth ed., Singapore: John Wiley \& Sons

37. Sehlotho N and Nyokong T 2006 Electrochim. Acta $\mathbf{5 1}$ 4463

38. Sivanesan A and John S A 2009 Electrochim. Acta 54 7458

39. Huethorst J A M S and Fokkink L G J 1995 Langmuir 112237
40. Tse Y H, Janda P, Lam H, Zhang J, Pietro W J and Lever A B P 1997 J. Porphyrins Phthalocyanines 13

41. Janda P, Kobayashi N, Auburn P R, Lam H, Leznoff C C and Lever A B P 1989 Can. J. Chem. 671109

42. Vijaikanth V, Capon J F, Gloaguen F, Schollhammer P, Talarmin J 2005 Electrochem. Commun. 7427

43. Maree S and Nyokong T 2000 J. Electroanal. Chem. 492 120

44. Mashazi P N, Ozoemena K I, Maree D M and Nyokong T 2006 Electrochim. Acta $\mathbf{5 1} 3489$

45. Kalimuthu P and John S A 2009 Electrochem. Commun. 11367 